University of Nebraska - Lincoln

DigitalCommons@University of Nebraska - Lincoln

USDA National Wildlife Research Center - Staff Publications
U.S. Department of Agriculture: Animal and Plant Health Inspection Service

August 1997

\title{
Aerial Photography Techniques to Estimate Populations of Laughing Gull Nests in Jamaica Bay, New York, 1992-1995
}

Richard A. Dolbeer

U.S. Department of Agriculture, National Wildlife Research Center

Jerrold L. Belant

U.S. Department of Agriculture, National Wildlife Research Center

Glen E. Bernhardt

U.S. Department of Agriculture, National Wildlife Research Center

Follow this and additional works at: https://digitalcommons.unl.edu/icwdm_usdanwrc

Part of the Environmental Sciences Commons

Dolbeer, Richard A.; Belant, Jerrold L.; and Bernhardt, Glen E., "Aerial Photography Techniques to Estimate Populations of Laughing Gull Nests in Jamaica Bay, New York, 1992-1995" (1997). USDA National Wildlife Research Center - Staff Publications. 137.

https://digitalcommons.unl.edu/icwdm_usdanwrc/137

This Article is brought to you for free and open access by the U.S. Department of Agriculture: Animal and Plant Health Inspection Service at DigitalCommons@University of Nebraska - Lincoln. It has been accepted for inclusion in USDA National Wildlife Research Center - Staff Publications by an authorized administrator of DigitalCommons@University of Nebraska - Lincoln. 


\title{
Aerial Photography Techniques to Estimate Populations of Laughing Gull Nests in Jamaica Bay, New York, 1992-1995
}

\author{
Richard A. DOlbeER, JeRrold L. BeLANT AND GLEN E. BERNHARDT \\ U.S. Department of Agriculture, National Wildlife Research Center, 6100 Columbus Avenue, \\ Sandusky, Ohio 44870 USA \\ Internet: A347dwrcsand@attmail.com
}

\begin{abstract}
We evaluated aerial photography (full coverage, using fixed-wing aircraft) and aerial video (transects, using helicopter) surveys to estimate the population of Laughing Gull (Larus atricilla) nests in Jamaica Bay, New York, during June 1992-1995. We counted 4,920 nests in the colony using aerial photography and estimated 5,367 nests using aerial video in 1992. In 1993-1995, we respectively counted 5,691, 5,095, and 6,126 nests in the colony using aerial photography, and estimated from ground plots that our counts differed from the actual number of nests by means of $-9 \%$ to $1 \%$. Overall (1993-1995) correction factors (by which to multiply the aerial photography nest counts) to estimate the mean and 95\% lower and upper CI range of the nest population were 1.04, 0.96 and 1.13 , respectively. Ninety-seven percent of nests identified using aerial photography or video had $\geq 1$ adult Laughing Gull present or within $1 \mathrm{~m}$ of the nest. The aerial video survey was less expensive $(\$ 2,100$ United States currency) than the aerial photography survey $(\$ 4,000)$. The estimated cost of a total count of nests from the ground is $\$ 6,700$ $\$ 9,600$. The aerial video survey provided an accurate estimate of the number of nests. Full-coverage aerial photography also provided an accurate estimate of nests in addition to habitat, nest distribution and nest density data. Received 13 June 1996, accepted 3 October 1996.
\end{abstract}

Key words.-Aerial photography, aerial survey, Jamaica Bay, Laughing Gull, Larus atricilla, nesting population.

Colonial Waterbirds 20(1): 8-13, 1997

Gulls (Larus spp.) have frequently been reported as a hazard to aircraft (Dahl 1984, Kull 1984, Seubert 1990, Sherigalin 1990). There was an increase in Laughing Gull $(L$. atricilla) collisions with aircraft at John F. Kennedy International Airport (JFKIA) during the 1980s related to an expanding nesting colony adjacent to the airport in Jamaica Bay (Dolbeer et al. 1989). This strike increase prompted various management actions including egg oiling, shooting gulls, and vegetation management (Griffin and Hoopes 1991, Dolbeer et al. 1993, Dolbeer and Bucknall 1994, Buckley and McCarthy 1994). Belant and Dolbeer (1993) predicted that these management programs would have a minimal effect on national Laughing Gull populations; however, an accurate estimate of the size of the nesting colony in Jamaica Bay was needed annually to assess effects on the local population. A ground-based count of this colony in 1990 totaled 7,579 nests (Griffin and Hoopes 1991).

Although the mark-relocate method of counting nests from the ground is considered the most reliable technique for estimating or censusing many colonial nesting species (Wilkinson 1991), the technique can be labor intensive and difficult to implement in tidal marshes interspersed with creeks. In addition, ground-based nest counts cause considerable disturbance in nesting colonies (Wilkinson 1991). A review of Laughing Gull nesting population surveys for the United States revealed that many estimates of colony size are based on partial ground counts or visual counts from the air that often are subjective, incomplete, and of questionable accuracy (Belant and Dolbeer 1993). Therefore, we evaluated aerial photography techniques to estimate the population of Laughing Gull nests in Jamaica Bay. Aerial surveys have been used frequently to estimate populations of nesting birds (Harris 1991, Hutchinson 1979, Sidle and Ferguson 1982, Wilkinson 1991). Our objective was to evaluate aerial surveys using photography and video in estimating the population of Laughing Gull nests in a colony in Jamaica Bay.

\section{METHODS}

Aerial surveys were conducted in June 1992-1995 over Joco (124 ha), Silver Hole ( 37 ha), East High Meadow (46 ha), and East Joco Island (36 ha) Marshes within Jamaica Bay, Gateway National Recreation Area, New York $\left(40^{\circ} 36^{\prime} \mathrm{N}, 73^{\circ} 47^{\prime} \mathrm{W}\right)$. These marshes are inter- 
spersed with tidal creeks and mosquito-control ditches. Dominant vegetation includes Spartina alterniflora, $S$. patens, and Distichlis spicata (Buckley and Buckley 1984, Burger 1983). The dates of our aerial surveys coincided with peak incubation and initial hatching of eggs for Laughing Gulls on these marshes (Buckley and Gurien 1986, Griffin and Hoopes 1991).

\section{Aerial Photography Survey}

Using a Cessna 310 aircraft, personnel from Aerographics Corporation (Bohemia, New York) flew 7 transects at approximately $300-\mathrm{m}$ intervals and at 370-m elevation over the marshes on 4 June 1992, 8 June 1993, 9 June 1994, and 16 June 1995. Flights were from 1000$1200 \mathrm{~h}$ with clear sky. Aerographics personnel took 60 overlapping black and white exposures during the 7 transects each year using a large format camera (Wild RC10 Precision Mapping Camera, $153 \mathrm{~mm}$ objective lens, $23 \times 23 \mathrm{~cm}$ negatives, Kodak $2405 \mathrm{XX}$ aerial film). Each exposure (scale 1:2424) covered approximately $554 \times 554 \mathrm{~m}$ (30.7 ha). We selected 22-30 of the exposures each year to obtain complete coverage of the 4 marshes.

We had $4 \times$ enlargement prints $(92 \times 92 \mathrm{~cm})$ made of the 22-30 exposures and covered each print with clear plastic, gridded in 1.9-ha blocks. Photographs were gridded to determine nest distribution and to avoid duplicate counts. An observer using a magnifying lens inspected each photograph and circled all nests detected with a permanent marker on the plastic overlay. A second observer reviewed each photograph.

In 1992, we did not conduct ground surveys of nests in the colony to assess the accuracy of our counts from photographs. In 1993, we established $730-\times 30-\mathrm{m}$ plots ( 5 on Joco and 2 on Silver Hole marshes) on 3 June. Plots were delineated with numbered $1-\times 1.5$-m cardboard markers staked flat to the ground at each corner and white cord stretched along the boundaries. Three to 6 observers searched each plot and marked nests with wire survey flags $(5 \times 8 \mathrm{~cm})$. The number of eggs and approximate location within the plot was recorded for each nest. The number of nests counted in these plots on the aerial photographs was then compared with the number counted on the ground. Ground counts were not referenced until after nests on aerial photographs were counted. In 1994-1995, this same procedure was repeated using 10 plots ( 7 on Joco and 3 on Silver Hole) established on 6 or 7 June.

For each year, 1993-1995, and for the 3 years combined, we determined correction factors by which nest counts from photographs should be multiplied to estimate mean and $95 \%$ confidence intervals (CI) for the nest population. These correction factors were based on the standard error of difference in ground and photograph counts for plots and Student $t_{0.05}$ values (Steel and Torrie 1960:44-46).

\section{Aerial Video Survey}

We flew 16 parallel transects $90 \mathrm{~m}$ over the marshes at approximately 130 -m intervals using a Bell Jet Ranger helicopter with a ground speed of about $30 \mathrm{kph}$ on 16 June 1992. The flight was from 1100-1300 h with clear sky. Each transect was taped using a SVHS video recorder (Panasonic model AG-450) at 5× magnification and pointed straight down through the open door. The estimate of nests was obtained by viewing the imagery and counting the number of nests visible on the monitor screen with the tape on "still". The tape was then advanced to the area immediately adjacent to the previous screen, paused, and nests were again counted. This procedure was used for each transect. The area of marsh visible on the $50-\mathrm{cm}$ monitor screen $(10.74 \mathrm{~m} \times 13.77 \mathrm{~m})$ at each pause was the unit of replication. Mean number of nests per ha $( \pm S E)$ was determined for each marsh and this value was extrapolated to estimate the number of nests for each entire marsh. The area (ha) of each marsh was determined using a compensating polar planimeter and a 1:15,800 scale aerial photograph. Because of disparity in sampling intensity (we did not survey the southern portion of Joco Marsh as intensively as anticipated) during the aerial video survey, we divided Joco Marsh into "north" and "south" units. Therefore, we did not obtain an overall standard error (SE) for this marsh.

We examined 500 nests on the photographs and 100 nests on the video in 1992 to estimate the proportion with Laughing Gulls either on, within $1 \mathrm{~m}$ of, or absent from nests. This sample was used to obtain minimum estimates of the number of nests with attending adults.

\section{RESULTS}

\section{Aerial Photography Survey}

We could not confidently delineate Laughing Gull nests on the unenlarged aerial photographs $(23 \times 23 \mathrm{~cm})$. However, nests were usually clearly visible on the $4 \times(92 \times 92$ $\mathrm{cm}$ ) enlargements as light gray- to white-colored circles about $1 \mathrm{~mm}$ in diameter, contrasting with the darker vegetation. In 19921995, we counted 4,920,5,691, 5,095 and 6,126 nests, respectively, on the photographs of the marshes (Table 1). Nest densities on the 1.9-ha blocks ranged from 0-271, 0-341, 0 494 , and $0-434$ in the respective years. In 1992, the highest concentrations of nests were found in the center of Joco Marsh in line with and about $0.8 \mathrm{~km}$ from the end of JFKIA's runway 4L (Fig. 1). The distribution of nests in 1993-1995 was similar to nest distribution in 1992 although relative numbers of nests among the 4 marshes varied (Table 2).

In 1993-1995, our counts of nests in the ground plots from aerial photographs differed from the actual number of nests counted in the plots by means of $-9 \%$ to $+1 \%$ (Table 3). If we adjust the photographic counts by these discrepancies, the estimated mean nest population was 6,032 in 1993 , 5,554 in 1994 and 6,065 in 1995. The overall (1993-1995) correction factors to estimate the mean and 95\% lower and upper CI 
Table 1. Estimated number of Laughing Gull nests on marshes in Jamaica Bay, New York, from aerial photography and aerial video surveys, June, 1992-1995.

\begin{tabular}{|c|c|c|c|c|c|}
\hline \multirow[b]{3}{*}{ Year } & \multirow[b]{3}{*}{ Aerial video } & \multicolumn{4}{|c|}{ Aerial photography } \\
\hline & & \multirow[b]{2}{*}{ Counted } & \multicolumn{3}{|c|}{ Corrected with $95 \% \mathrm{CI}^{1}$} \\
\hline & & & $\overline{\mathrm{X}}$ & Lower & Upper \\
\hline 1992 & 5,367 & 4,920 & 5,117 & 4,723 & 5,560 \\
\hline 1993 & & 5,691 & 6,032 & 5,008 & 7,512 \\
\hline 1994 & & 5,095 & 5,554 & 5,095 & 6,063 \\
\hline 1995 & & 6,126 & 6,065 & 5,085 & 7,596 \\
\hline
\end{tabular}

${ }^{1}$ Estimated values based on correction values in Table 3. Because no ground plots were sampled in 1992, the mean correction value for 1993-1995 was used to adjust 1992 data. Correction values for the respective individual years were used in 1993-1995.

range of the nest population were 1.04, 0.96 and 1.13 , respectively.

\section{Aerial Video Survey}

Nests were clearly visible from the video imagery, averaging about $18 \mathrm{~mm}$ in diameter on the $50-\mathrm{cm}$ monitor screen. We counted nests in 934 screens (replicates), which comprised $5.5 \%$ overall coverage of the four marshes. Our estimates ( \pm SE) for "north" and "south" JoCo Marsh were $3742 \pm 482$ and 383 \pm 275 nests, respectively. Estimated number of nests from the aerial video survey in 1992 were similar to the number of nests counted in 1992 using photographs (Table 1).

For each survey in 1992, we estimated $97 \%$ of nests had adult Laughing Gulls present or within $1 \mathrm{~m}$ of the nest, suggesting most nests observed were occupied. Over $99 \%$ (590) of the 594 nests counted from the ground in plots in 1993-1995 had $\geq 1 \mathrm{egg}$, indicating nest counts were made at the peak of incubation.

\section{Costs of Surveys}

The cost of an aerial photography survey, including the flight, initial 60 photographs, and enlargements was $\$ 3,200$ (United States currency). To obtain total counts of nests from photographs of each marsh required 40 person-h. Ground counts required an additional 30 person-h. Assuming a labor cost of $\$ 12.00 / \mathrm{h}$, the entire survey cost about $\$ 4,000$. Cost of the aerial video survey (assuming video equipment is available), in- cluding flight time and 30 person-h $(\$ 12.00$ / $h$ ) for viewing the imagery and summarizing data, was about $\$ 2,100$. To conduct a single total count of nests from the ground on these marshes would require eight experienced people for 7 to 10 10-h days, representing 560-800 person-h (E. Hoopes, Univ. Mass.-Amherst, pers. comm.). At $\$ 12.00 / \mathrm{h}$, this survey would cost between $\$ 6,700$ and $\$ 9,600$; excluding travel, per diem, and equipment costs.

\section{DISCUSSION}

Because of low herbaceous cover, lack of overhead cover, and high contrast between nests and adjacent vegetation, we believe aerial photography or video surveys are suitable for estimating the number of Laughing Gull nests in habitats such as found in Jamaica Bay. We undoubtedly overlooked some nests and miscounted other objects as nests on the aerial photographs; however, counts from ground plots indicated errors were $<10 \%$. Overall (1993-1995), counts from photographs needed to be adjusted by $-4 \%$ to $13 \%$ to encompass the $95 \%$ CI of the nest population.

The counts of nests from each marsh determined from the aerial photography survey in 1992 were within the respective standard error values calculated from the aerial video survey. After correcting for bias via counting nests from the ground, the two techniques should provide similar estimates for a given nesting colony. Wilkinson (1991) found that counts of Royal (Sterna maxima) 


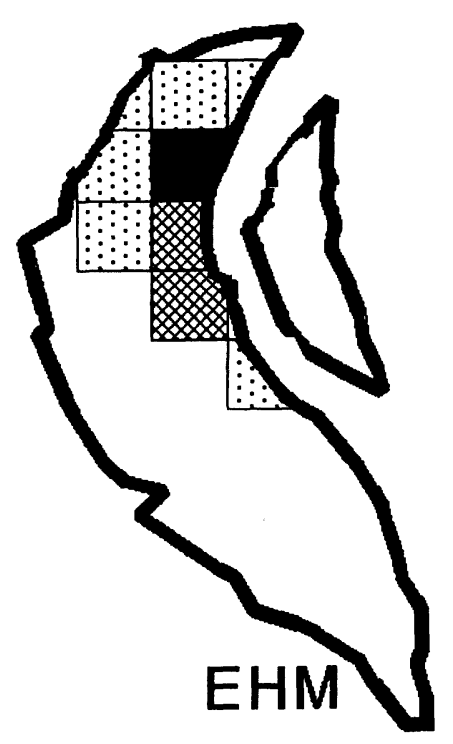

NO. OF NESTS

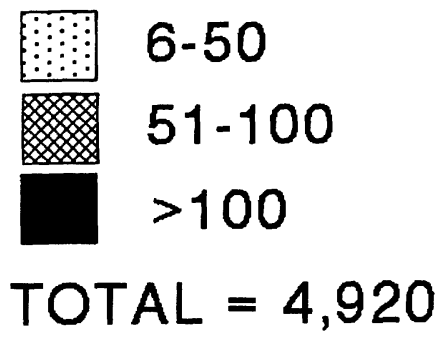

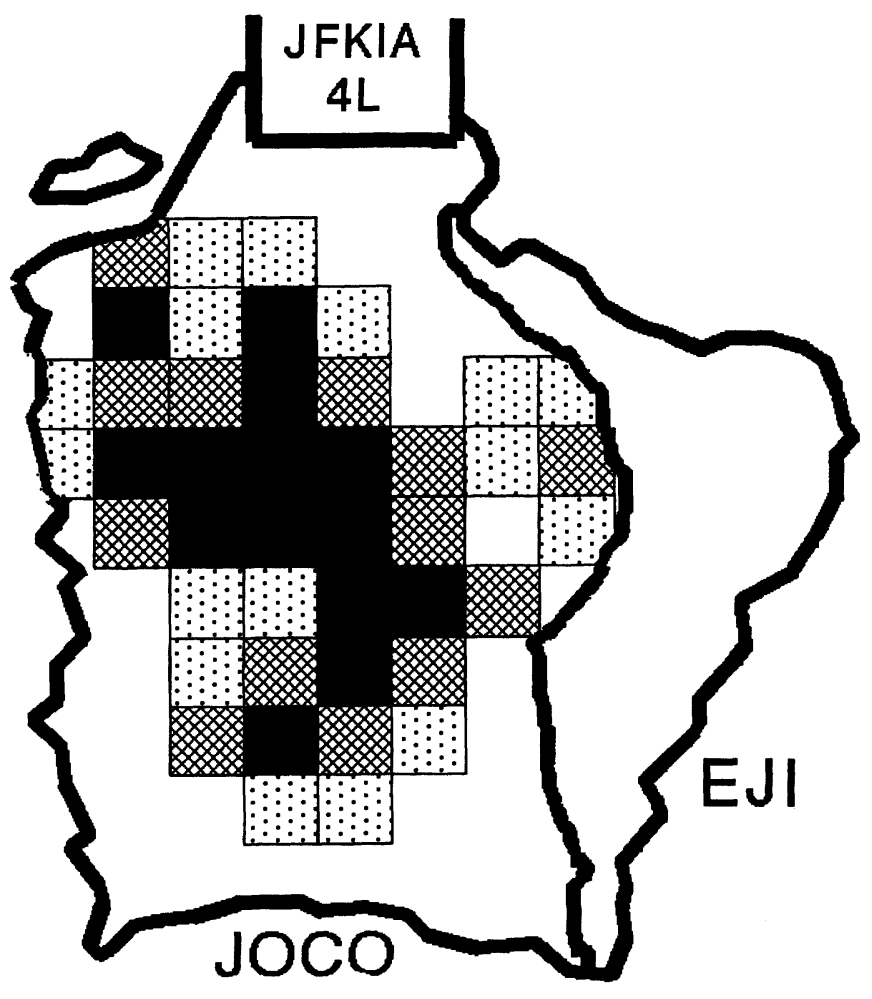

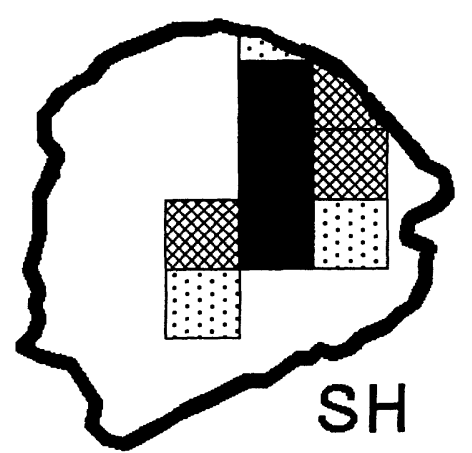

Figure 1. Distribution and relative abundance of Laughing Gull nests by 1.9-ha blocks on 4 marshes (EHM = East High Meadow, JOCO = Joco Island, EJI = East Joco Island, SH = Silver Hole) in Jamaica Bay, New York adjacent to runway 4L, John F. Kennedy International Airport (JFKIA), as determined from aerial photography, 4 June 1992.

and Sandwich Tern (S. sandvicensis) nests using aerial photographs were in agreement $( \pm 10 \%)$ with single ground and transect counts.

The high level of nest occupancy (97\% for each survey) observed demonstrated that these techniques caused minimal disturbance, even when using a helicopter at $90-\mathrm{m}$ elevation. In contrast, nest counts from the ground, particularly multiple counts of the same colony, can cause considerable disturbance (Wilkinson 1991).
The aerial video survey was the most time- and cost-efficient method to obtain an estimate of the nesting population of Laughing Gulls. However, data were more limited than were data collected using aerial photography, providing only an estimate rather than a total count of nests. Other advantages of aerial photography include the ability to better evaluate habitat, nest spacing and distribution, and nest density. Both techniques require substantially less time than would nest counts from the ground of the same ar- 
Table 2. Estimated number of Laughing Gull nests on four marshes from aerial video and aerial photography surveys, Jamaica Bay, New York, June 1992-1995.

\begin{tabular}{|c|c|c|c|c|c|c|}
\hline \multirow[b]{2}{*}{ Marsh } & \multirow[b]{2}{*}{ Area $(\mathrm{Ha})$} & \multirow{2}{*}{$\begin{array}{c}\begin{array}{c}\text { Aerial video } \\
(\mathrm{SE})\end{array} \\
1992\end{array}$} & \multicolumn{4}{|c|}{ Aerial photography (Corrected) ${ }^{1}$} \\
\hline & & & 1992 & 1993 & 1994 & 1995 \\
\hline Joco & 124 & 4,125 & 3,998 & 4,002 & 3,755 & 4,595 \\
\hline Silver Hole & 37 & $772(131)$ & 670 & 1,460 & 1,240 & 757 \\
\hline E. H. Meadow & 46 & $443(144)$ & 449 & 516 & 414 & 479 \\
\hline E. Joco Is. & 36 & $27(27)$ & 0 & 54 & 145 & 234 \\
\hline Total & 243 & 5,367 & 5,117 & 6,032 & 5,554 & 6,065 \\
\hline
\end{tabular}

${ }^{1}$ Estimated mean values based on correction values in Table 3. Because no ground plots were sampled in 1992, the mean correction value for 1993-1995 was used to adjust 1992 data. Correction values for the respective individual years were used in 1993-1995.

Table 3. Mean difference in number of Laughing Gull nests counted from ground and from aerial photographs in 30- $\times 30-\mathrm{m}$ plots and estimated correction factors for adjusting aerial photograph counts to estimate mean number of nests (and 95\% CI), Jamaica Bay, New York, June, 1993-1995.

\begin{tabular}{|c|c|c|c|c|c|c|c|c|}
\hline \multirow[b]{2}{*}{ Year } & \multirow[b]{2}{*}{ No. of plots } & \multicolumn{2}{|c|}{$\begin{array}{l}\text { No. of nests counted } \\
\text { from ground }\end{array}$} & \multicolumn{2}{|c|}{$\begin{array}{l}\text { Nest count difference: } \\
\text { photographs minus } \\
\text { ground }\end{array}$} & \multicolumn{3}{|c|}{$\begin{array}{l}\text { Correction factor for photograph } \\
\text { count }(\overline{\mathrm{X}} \text { and } 95 \% \mathrm{CI})^{1}\end{array}$} \\
\hline & & $\overline{\mathrm{X}}$ & SD & $\overline{\mathrm{X}}$ & SD & $\overline{\mathrm{X}}$ & Lower & Upper \\
\hline 1993 & 7 & 15.71 & 7.29 & -0.86 & 3.18 & 1.06 & 0.88 & 1.32 \\
\hline 1994 & 10 & 25.00 & 12.32 & -2.00 & 2.79 & 1.09 & 1.00 & 1.19 \\
\hline 1995 & 10 & 23.40 & 12.97 & 0.20 & 6.60 & 0.99 & 0.83 & 1.24 \\
\hline Total & 27 & 22.00 & 10.22 & -0.89 & 4.59 & 1.04 & 0.96 & 1.13 \\
\hline
\end{tabular}

${ }^{1}$ Amount by which nest counts from photographs should be multiplied to estimate mean and $95 \%$ CI for nest population, based on standard error of difference in ground and photograph counts for plots and Student $t_{0.05}$ values with 6, 9, 9 and $26 \mathrm{df}$ for 1993, 1994, 1995 and 1993-1995, respectively.

ea. These aerial survey techniques likely are suitable for assessing nesting populations of other species of colonial waterbirds, provided nests are not obscured by vegetation and colonies are at least moderately dense. Although frequently not done at present (Belant and Dolbeer 1993), photography or video should be implemented in aerial surveys of colonial nesting waterbirds to provide a permanent record.

\section{ACKNOWLEDGMENTS}

We thank personnel from Aerographics Corporation and National Helicopter Corporation, Inc. for their assistance conducting the aerial surveys. M. Chevalier, S. D. Garber, J. K. Gartner, and A. M. Sloane of the Port Authority of New York and New Jersey (PANYNJ) provided valuable logistical support and advice. We thank the National Park Service, especially D. Riepe, for providing boat transportation and assistance in conducting ground surveys. J. Allen, W. Beck, J. L. Bucknall, J. E. Forbes, S. W. Gabrey, S. K. Ickes and E. J. Marshall of the USDA also provided assistance. This study was funded under a cooperative agreement with the PANYNJ.

\section{REFERENCES CiteD}

Belant, J. L. and R. A. Dolbeer. 1993. Population status of nesting laughing gulls in the United States, 19771991. American Birds 47: 220-224.

Buckley, P. A. and F. G. Buckley. 1984. Expanding double-crested cormorants and laughing gull populations on Long Island, NY. Kingbird 34: 147-155.

Buckley, P. A. and M. M. Gurien. 1986. An ecological approach to the control of laughing gulls at John F. Kennedy International Airport, New York City. Final Report for National Park Service Cooperative Research Unit., Rutgers University, New Brunswick, New Jersey.

Buckley, P. A. and M. G. McCarthy. 1994. Insects, vegetation, and the control of laughing gulls (Larus atricilla) at Kennedy International Airport, New York City. Journal of Applied Ecology 31: 291-302.

Burger, J. 1983. Jamaica Bay studies III: abiotic determinants of distribution and abundance of gulls (Larus). Estuarine, Coastal and Shelf Science 16: 191-216.

Dahl, H. 1984. The bird strike situation and its ecological background in the Copenhagen Airport, Kastrup. Pages 287-290, in Proceedings Wildlife Hazards to Aircraft Conference and Workshop (M. J. Harrison, S. A. Gauthreaux, Jr., and L. A. Abron-Robinson, Eds.). U.S. Department of Transportation, Federal Aviation Administration, Washington, D.C. 
Dolbeer, R. A., J. L. Belant and J. L. Sillings. 1993. Shooting gulls reduces strikes with aircraft at John $F$. Kennedy International Airport. Wildlife Society Bulletin 21: 442-450.

Dolbeer, R. A. and J. L. Bucknall. 1994. Shooting gulls reduces strikes with aircraft at John F. Kennedy International Airport, 1991-1993. Bird Strike Committee Europe 22: 375-396.

Dolbeer, R. A., M. Chevalier, P. P. Woronecki and E. B. Butler. 1989. Laughing gulls at JFK Airport: safety hazard or wildlife resource? Proceedings of Eastern Wildlife Damage Control Conference 4: 37-44.

Griffin, C. R. and E. M. Hoopes. 1991. Birds and the potential for bird strikes at John F. Kennedy International Airport. Final Report, National Park Service, Gateway National Recreation Area, Brooklyn, New York and National Park Service Coastal Research Center, Kingston, Rhode Island.

Harris, J. O. 1991. Colonial bird nesting on Breton National Wildlife Refuge. Pages 139-141, in Proceedings of the coastal nongame workshop held 10-12 September 1991 at Gainesville, Florida (D. P. Jennings, compiler). U.S. Fish and Wildlife Service, Office of Information Transfer, Fort Collins, Colorado.

Hutchinson, A. E. 1979. Estimating numbers of colonial nesting seabirds-a comparison of techniques. Colonial Waterbirds 3: 235-244.
Kull, R. C., Jr. 1984. 1983 Air Force bird strikes. Pages 4957 , in Proceedings wildlife hazards to aircraft conference and workshop (M. J. Harrison, S. A. Gauthreaux, Jr., and L. A. Abron-Robinson, Eds.). U.S. Department Transportation, Federal Aviation Administration, Washington, D.C.

Seubert, J. L. 1990. Reducing gull hazards to aviation by controlling nesting populations. Bird Strike Committee Europe 20: 613-642.

Sherigalin, J. E. 1990. Bird strike analysis in Estonia 1951-1988. Bird Strike Committee Europe 20: 183199.

Sidle, J. G. and E. L. Ferguson. 1982. White pelican populations at Chase Lake, North Dakota, evaluated by aerial photography. Prairie Naturalist 14: 13-26.

Steel, R. G. D. and J. H. Torrie. 1960. Principles and procedures of statistics. McGraw Hill Book Co., New York.

Wilkinson, P. M. 1991. Surveys of colonial nesting seabirds in South Carolina. Pages 84-89, in Proceedings of the coastal nongame workshop held 10-12 September 1991 at Gainesville, Florida (D. P. Jennings, compiler). U.S. Fish and Wildlife Service, Office of Information Transfer, Fort Collins, Colorado. 